\title{
Economic Burden of Treatment-Resistant Depression on the U.S. Health Care System
}

\author{
Matthew Sussman, MA; Amy K. O'Sullivan, PhD; Ankit Shah, MS;
} Mark Olfson, MD, MPH; and Joseph Menzin, PhD

\begin{abstract}
BACKGROUND: Treatment-resistant depression (TRD), defined as episodes of depression that do not respond to $\geq 2$ lines of adequate depression therapy, is associated with a high economic burden. Although the economic burden of TRD is reported elsewhere, its exact magnitude and current value is uncertain due to differences in methodology in TRD identification.
\end{abstract}

OBJECTIVE: To compare all-cause health care resource utilization (HCRU) and associated health care payments among patients with TRD and those with depression but without TRD, using administrative claims data.

METHODS: This retrospective cohort study used data from the Truven Health MarketScan Commercial and Medicare Supplemental Databases (0ctober 1, 2008-September 30, 2016). All patients were aged $\geq 18$ years, newly diagnosed with depression ( $\geq 1$ inpatient admission or $\geq 2$ outpatient visits with a primary or secondary depression diagnosis), and newly treated with depression therapy. The population included patients with and without TRD. Patients with TRD were defined as having been treated with $\geq 3$ courses of depression therapy within a 360 -day period (initiation of the third course served as the TRD index date), while patients without TRD (non-TRD) were defined as having been treated with 2 courses of depression therapy. TRD and non-TRD cohorts were matched using propensity scores. Using the TRD index date of their matched TRD pair, nonTRD patients were assigned a simulated index date following second-line therapy. Eligible TRD and non-TRD patients were continuously enrolled from a 12-month baseline period before the first course of therapy through a 12-month follow-up period beginning with the TRD index date and simulated index date, respectively. Annual all-cause HCRU and associated payments (2016 U.S. dollars) were assessed in aggregate and by place of service during the follow-up period and were compared between the matched cohorts using nonparametric Wilcoxon signed-rank tests.

RESULTS: The matched analysis included 800 patients in each cohort. For both cohorts, the mean age of patients was 39 years, and $60 \%$ were female. All clinical characteristics and all-cause HCRU were comparable at baseline. Compared with non-TRD patients, TRD patients had a significantly higher mean number of all-cause emergency department (ED) visits (0.29 vs. 0.24 ), outpatient visits ( 18.0 vs. 13.4$)$, and prescriptions (30.0 vs. 24.0 ; all $P<0.05)$ during the 12-month follow-up period. The TRD cohort also had significantly higher mean total all-cause health care payments $(\$ 9,890$ vs. $\$ 6,848 ; P<0.001)$ and mean payments by place of service (ED: $\$ 518$ vs. $\$ 408$; outpatient: $\$ 3,603$ vs. $\$ 2,585$; pharmacy: $\$ 2,613$ vs. $\$ 1,837$; all $P<0.05)$ compared with the non-TRD cohort.

CONCLUSIONS: In relation to propensity score-matched non-TRD patients, TRD patients used significantly more resources (ED visits, outpatient visits, and number of prescriptions) and had significantly higher overall health care payments. These results serve to highlight the unmet need in patients with TRD, suggesting that improved and more effective management of these patients may help reduce the economic burden of disease.

J Manag Care Spec Pharm. 2019;25(7):823-35

Copyright $\odot 2019$, Academy of Managed Care Pharmacy. All rights reserved.

\section{What is already known about this subject}

Patients with treatment-resistant depression (TRD) are defined as patients with depression who have not responded to consecutive treatments with at least 2 different antidepressants that are used for a sufficient length of time, at an adequate dose, and with adequate affirmation of treatment adherence.

The Sequenced Treatment Alternatives to Relieve Depression trial found lower remission rates in the third and fourth treatment steps, highlighting the importance of treating patients with an effective third-line therapy following the failure of 2 previous lines of therapy.

While the economic burden of TRD has been extensively evaluated, few published studies have assessed health care resource utilization and payments associated with TRD following thirdline treatment initiation.

\section{What this study adds}

In commercially insured and Medicare patients with depression, patients with TRD had more than $\$ 3,000$ excess all-cause total health care payments in the 12 months following identification of TRD (i.e., initiation of third-line treatment) compared with patients without TRD.

Significant drivers of excess economic burden associated with TRD included health care payments related to ED visits, outpatient visits, and number of prescriptions.

Improved and more effective management of these patients, either before progression to TRD or following progression to $\mathrm{TRD}$, may help reduce the economic burden of disease

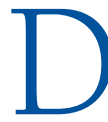
epression is a persistent mood disorder characterized by significant social, educational, and vocational impairments and has a lifetime prevalence of approximately 20.6\%. ${ }^{1}$ The economic burden associated with depression was estimated to be $\$ 210.5$ billion in the United States (2010), with 45\% attributable to direct health care costs. ${ }^{2}$ Treatment for depression focuses on reducing or eliminating the symptoms of depression; however, approximately 63\% of patients do not achieve an adequate response to a first-line antidepressant after 6-12 weeks of treatment. ${ }^{3}$ The American Psychiatric Association (APA) guidelines recommend revising the treatment plan for patients who do not fully respond to an adequate treatment over a 4 - to 8 -week time frame. ${ }^{4}$ 
For patients with depression who do not respond to initial treatment, one option includes escalating the dose of treatment, especially if the maximum level has not been reached. Patients who have not had at least a partial response to the initial medication regimen may be switched to a different therapy or may receive an augmentation therapy. Patients may switch to an antidepressant from the same pharmacological class (e.g., from one selective serotonin reuptake inhibitor [SSRI] to another SSRI), switch to an antidepressant from a different monoamine-based class (e.g., from an SSRI to a serotonin norepinephrine reuptake inhibitor [SNRI]), or augment their initial antidepressant therapy with other depression therapies (e.g., with a monoamine oxidase inhibitor [MAOI] antidepressant, a second-generation antipsychotic, or a nonantidepressant therapy [e.g., lithium, thyroid hormone, stimulants, dopaminergics, anticonvulsants, folate]). ${ }^{4}$ For some patients, electroconvulsive therapy (ECT) may also be considered.

While the precise definition of refractory or resistant depression is inconsistent in the literature, patients have been classified as having treatment-resistant depression (TRD) when consecutive treatments with at least 2 different antidepressants, used for a sufficient length of time (4-8 weeks), at an adequate dose, and with adequate affirmation of treatment adherence, fail to induce a clinically meaningful improvement in the disease symptoms..$^{5-7}$ Due to the lack of consistency in definitions of TRD, the prevalence of TRD varies widely in the literature, with ranges of approximately 10\%-45\%. ${ }^{8-13}$

The Sequenced Treatment Alternatives to Relieve Depression $\left(\mathrm{STAR}^{*} \mathrm{D}\right)$ trial compared long-term treatment outcomes among major depressive disorder (MDD) patients, including remission as measured by the 16-item Quick Inventory of Depressive Symptomatology-Self-Report, associated with 4 successive treatment steps. ${ }^{13}$ The authors found lower remission rates when more treatment steps were required, especially in the third and fourth steps. Specifically, the remission rate fell dramatically when moving from the first and second treatment steps $(36.8 \%$ and $30.6 \%$, respectively) to the third and fourth treatment steps (13.7\% and $13.0 \%$, respectively). Cumulatively, approximately $45 \%$ of patients continuing with the program did not achieve remission after 2 treatment steps, highlighting the importance of reducing progression to third-line therapy (i.e., TRD).

According to a recent literature review, the clinical and humanistic burden among patients with TRD is higher compared with patients with MDD who respond to treatment. ${ }^{14}$ Patients with TRD were more likely to have some psychiatric comorbid conditions (i.e., malaise or fatigue, anxiety, and personality disorder); suicidal ideation; and lower quality of life than patients with treatment-responsive depression. Additionally, the economic burden associated with TRD, including direct medical cost burden and indirect cost burden in the form of lost productivity, has been reported in the literature. ${ }^{8-12,15-20}$ When compared with an MDD patient without TRD, a typical TRD patient is expected to accrue between 1.5-2 times the health care costs., ${ }^{9,1}$ The expected annual medical costs (non-excess) for a single TRD patient have been estimated to be as high as $\$ 17,590$ in the 12 months following receipt of the first antidepressant medication. ${ }^{9}$ Moreover, a recent study found that TRD patients have, on average, 35.8 work-loss days per patient per year, which is 1.7 and 6.2 times the work-loss rate in non-TRD MDD and non-MDD patients, respectively. ${ }^{8}$

Despite the existing literature, few published studies have assessed health care resource utilization (HCRU) and payments associated with TRD following third-line treatment initiation. The primary objective of this study was to assess the incremental effect of TRD during an observation period beginning with TRD onset through 12 months following onset. This unique approach allows for simplified interpretations of results concerning the annual financial burden attributable to TRD. ${ }^{21}$ A secondary objective was to compare our methods for TRD case identification and observation periods for analysis with the currently published literature in an effort to inform our study design and to raise important differences between our design and that of the published literature.

\section{Methods}

\section{Study Overview}

A retrospective cohort analysis was conducted on patients with depression using deidentified administrative claims data from October 1, 2008, to September 30, 2016. The 2 cohorts analyzed patients with TRD (TRD cohort) and without TRD (non-TRD cohort). TRD patients were identified by using previously published administrative claims-based algorithms. ${ }^{9-11,13-18}$ Analyses compared the economic burden associated with patients with TRD to the burden associated with patients with depression but without TRD over a 12-month follow-up period.

\section{Data Source}

The data source for this study was the Truven Health MarketScan databases, which consist of the MarketScan Commercial Claims and Encounters database and the MarketScan Medicare Supplemental database..$^{22}$ The MarketScan Commercial Claims and Encounters database contains data for several million individuals annually who are covered by employer-sponsored private health insurance in the United States. The population covers employees, their spouses, and dependents aged 0-64 years. The MarketScan Medicare Supplemental database has the same structure as the commercial database but covers retirees with Medicare supplemental insurance paid by employers. This analysis was based on commercially available administrative claims data and did not involve direct contact with patients. Ethical approval did not need to be obtained for this study. 


\section{Patient Selection}

The population of interest for this analysis included adult patients (aged $\geq 18$ years) newly diagnosed with depression and newly treated with an antidepressant. Patients were classified as TRD or non-TRD based on the following criteria.

The TRD population included patients who had $\geq 1$ inpatient admission or $\geq 2$ outpatient visits with a primary or secondary depression diagnosis between October 1, 2009, and September 30, 2014 (i.e., depression diagnosis date). A depression diagnosis was identified by International Classification of Diseases, Ninth Revision, Clinical Modification (ICD-9-CM) diagnosis codes for depression (296.2x, 296.3x, 300.4, 309.0, 309.1, and 311) or International Classification of Diseases, Tenth Revision, Clinical Modification (ICD-10-CM) diagnosis codes (F32.0-F32.5, F32.9, F33.0-F33.3, F33.41, F33.42, F33.9, F34.1, and F43.21). TRD patients were aged $\geq 18$ years as of the depression diagnosis date, were treated with $\geq 3$ lines of depression pharmacotherapy, and had continuous medical and pharmacy benefits enrollment in the 12 months before the depression diagnosis date (i.e., baseline period) through the 12 months after third-line initiation (i.e., follow-up period).

TRD patients were excluded from the study sample if they had a depression diagnosis in the 12-month baseline period; an antidepressant prescription fill in the 12-month baseline period; a prescription fill for trazodone or amitriptyline any time during the entire 8-year study window (October 1, 2008-September 30, 2016); initiated augmentation treatment as first-line therapy; had a primary or secondary diagnosis of schizophrenia, delusional disorders, other nonorganic psychoses, dementias, mental retardation, senility without mention of psychosis, and/or bipolar disorder any time during the entire 8-year study window; or had no direct medical payment data. The TRD cohort patient timeline is described in Appendix A (available in online article).

The patient inclusion criteria for the non-TRD cohort were similar to those for the TRD cohort; however, non-TRD patients received only 2 lines of depression pharmacotherapy and did not receive a third-line therapy. Our definition of the nonTRD cohort did not include patients receiving only 1 line of therapy, since their outcomes were expected to be better than patients receiving 2 lines of therapy, as evidenced by lower rates of remission from the STAR*D trial. Our assessment of the economic burden of TRD, then, would be more conservative. Non-TRD patients must have had continuous medical and pharmacy benefits enrollment in the 12 months before the depression diagnosis date through 360 days following the firstline index date (i.e., the antidepressant treatment identification period). Patients in the non-TRD cohort were propensity scorematched 1:1 to patients in the TRD cohort, and only matched pairs were included in the final dataset.

\section{Definition of Lines of Therapy}

In order to define third-line therapy, each previous line of therapy (i.e., first-line, second-line) must be defined first. Firstline therapy was defined as an antidepressant prescription fill within 14 days following the depression diagnosis date and treatment for $\geq 44$ days within 2 consecutive 30 -day segments. The criterion requiring patients to be on antidepressant therapy for at least 44 days was based on the APA practice guidelines that indicate that antidepressant therapy should be maintained for a sufficient duration of 4-8 weeks before adjusting the treatment plan; for this study, an average of 6 weeks was adopted. ${ }^{4}$

Second-line therapy was defined as a switch to a different antidepressant in the same or different class than the first-line therapy, or augmentation of first-line therapy with another antidepressant or second-generation antipsychotic in the 360 days following first-line therapy. Similar to first-line therapy, patients must have been treated for $\geq 44$ days within 2 consecutive 30 -day segments to qualify as second-line treatment.

Third-line therapy was defined as a switch to a different antidepressant in the same or different class than the first- and second-line therapies, or augmentation of second-line therapy with another antidepressant or second-generation antipsychotic in the 360 days following first-line therapy. The date of initiation of third-line therapy was defined as the TRD index date.

\section{Study Time Periods}

This study included the following 3 time periods of interest:

- Baseline period, a fixed 12-month period before the depression diagnosis date

- Antidepressant treatment identification period, a variable period of $\leq 360$ days following first-line treatment initiation used to identify second- and third-line therapies

- Follow-up period, a fixed 12-month period following the index date used to measure all-cause and depression-related HCRU and payments

\section{Propensity Score Matching (TRD and Non-TRD Cohorts)}

Patients in the non-TRD cohort were matched 1:1 to patients in the TRD cohort by the propensity score-matching (PSM) method, using the greedy nearest neighbor approach, with a caliper of 0.05 of the standard deviation (SD) of the estimated logit. The propensity score was defined as the probability of being classified as TRD (dependent variable) based on a set of baseline characteristics, including age, sex, geographic region, metropolitan statistical area (MSA), Charlson Comorbidity Index score, baseline comorbid conditions, provider type, presence of all-cause baseline HCRU, and number of baseline prescriptions (Table 1). Baseline comorbid conditions used in PSM were required to have a prevalence of $>5 \%$ in either the matched TRD or non-TRD cohorts and included opioid use disorder, pain, anxiety disorder, cardiovascular disease, and 
Economic Burden of Treatment-Resistant Depression on the U.S. Health Care System

\section{TABLE 1 Baseline Demographics and Clinical Characteristics Among Unmatched and Matched Cohorts}

\begin{tabular}{|c|c|c|c|c|c|c|c|c|}
\hline \multirow{3}{*}{$\begin{array}{l}\text { Characteristic } \\
\text { Mean (SD) age }\end{array}$} & \multicolumn{4}{|c|}{ Unmatched } & \multicolumn{4}{|c|}{ Propensity Score Matched } \\
\hline & $\begin{array}{c}\text { TRD } \\
(\mathrm{n}=1,112)\end{array}$ & $\begin{array}{c}\text { Non-TRD } \\
(\mathrm{n}=10,734)\end{array}$ & \multirow{2}{*}{$\begin{array}{c}\begin{array}{c}\text { Standard } \\
\text { Differences }\end{array} \\
-9.4 \\
\end{array}$} & \multirow{2}{*}{$\frac{P \text { Value }}{0.019}$} & $\begin{array}{c}\text { TRD } \\
(\mathrm{n}=800)\end{array}$ & $\begin{array}{l}\text { Non-TRD } \\
(\mathrm{n}=800)\end{array}$ & \multirow{2}{*}{$\begin{array}{c}\begin{array}{c}\text { Standard } \\
\text { Differences }\end{array} \\
-2.3 \\
\end{array}$} & \multirow{2}{*}{$\frac{P \text { Value }}{0.481}$} \\
\hline & $38.8 \quad(14.1)$ & $40.1 \quad(14.7)$ & & & $38.6(14.2)$ & $39.3(15.0)$ & & \\
\hline Female, n (\%) & $674 \quad(60.6)$ & $6,820 \quad(63.5)$ & 5.2 & 0.058 & $485(60.6)$ & $478 \quad(59.8)$ & -0.8 & 0.753 \\
\hline \multicolumn{4}{|l|}{ Geographic region, n (\%) } & 0.007 & & & & 0.997 \\
\hline Northeast & $229(20.6)$ & $1,782 \quad(16.8)$ & 9.7 & & $170(21.3)$ & $167(20.9)$ & 2.1 & \\
\hline South & $360 \quad(32.4)$ & $3,617 \quad(34.2)$ & -2.3 & & $264(33.0)$ & $265(33.1)$ & 1.0 & \\
\hline West & $245(22.0)$ & $2,392 \quad(22.6)$ & -1.2 & & $171 \quad(21.4)$ & $170 \quad(21.3)$ & -0.2 & \\
\hline Midwest & $264(23.7)$ & $2,792 \quad(26.4)$ & & & $195(24.4)$ & $198(24.8)$ & & \\
\hline MSA, n (\%) & $951 \quad(86.5)$ & $8,863 \quad(83.7)$ & 8.1 & 0.014 & $701 \quad(87.6)$ & $703 \quad(87.9)$ & -3.9 & 0.936 \\
\hline Mean (SD) CCI score & $0.2 \quad(0.7)$ & $0.3 \quad(0.8)$ & -5.5 & 0.114 & $0.2 \quad(0.7)$ & $0.3 \quad(0.8)$ & -2.3 & 0.510 \\
\hline \multicolumn{9}{|l|}{ Selected comorbid conditions, ${ }^{a} \mathrm{n}(\%)$} \\
\hline Opioid use disorder & $374 \quad(33.6)$ & $3,578 \quad(33.3)$ & NA & 0.841 & $279(34.9)$ & $247(30.9)$ & NA & 0.098 \\
\hline Pain & $244 \quad(21.9)$ & $2,410 \quad(22.5)$ & -1.5 & 0.734 & $171 \quad(21.4)$ & $158(19.8)$ & 4.3 & 0.451 \\
\hline Anxiety disorder & 132 (11.9) & $1,070 \quad(10.0)$ & 6.2 & 0.048 & $99(12.4)$ & $92(11.5)$ & 3.2 & 0.630 \\
\hline Cardiovascular disease & $74 \quad(6.7)$ & $790 \quad(7.4)$ & -2.0 & 0.431 & $56 \quad(7.0)$ & $57 \quad(7.1)$ & 1.1 & 1.000 \\
\hline Obesity & $(4.9)$ & $(5.7)$ & -4.5 & 0.246 & $(5.5)$ & $(4.5)$ & 0.9 & 0.396 \\
\hline \multicolumn{4}{|l|}{ Provider type, n (\%) } & $<0.001$ & & & & 0.719 \\
\hline Family practice & $354 \quad(32.8)$ & $4,002 \quad(38.4)$ & & & $255 \quad(31.9)$ & $257(32.1)$ & & \\
\hline Psychiatrist & $184 \quad(17.1)$ & $1,278 \quad(12.3)$ & 12.8 & & $147(18.4)$ & $149(18.6)$ & -0.5 & \\
\hline Internal medicine & $135(12.5)$ & $1,275 \quad(12.2)$ & 1.0 & & $95 \quad(11.9)$ & $108(13.5)$ & -1.7 & \\
\hline Other & $406 \quad(37.6)$ & $3,857 \quad(37.0)$ & 1.1 & & $303(37.9)$ & $286(35.8)$ & 3.9 & \\
\hline \multicolumn{9}{|l|}{ All-cause resource use } \\
\hline Patients with a hospitalization, n (\%) & $97 \quad(8.7)$ & $(8.4)$ & 0.7 & 0.691 & $(8.9)$ & $(8.3)$ & -0.7 & 0.723 \\
\hline Patients with an ED visit, $\mathrm{n}(\%)$ & $195 \quad(17.5)$ & $2,001 \quad(18.6)$ & -3.1 & 0.395 & $148(18.5)$ & $124(15.5)$ & 5.7 & 0.123 \\
\hline Patients with an outpatient visit, $\mathrm{n}(\%)$ & $1,033 \quad(92.9)$ & $9,884 \quad(92.1)$ & 3.1 & 0.379 & $742(92.8)$ & $745(93.1)$ & 2.9 & 0.848 \\
\hline Patients with an other visit, ${ }^{b} \mathrm{n}(\%)$ & $314(28.2)$ & $3,051 \quad(28.4)$ & -0.3 & 0.917 & $228(28.5)$ & $221(27.6)$ & 2.5 & 0.744 \\
\hline Mean (SD) number of prescriptions & $14.5 \quad(16.2)$ & \begin{tabular}{|ll}
$14.4 \quad(17.6)$ \\
\end{tabular} & \begin{tabular}{|l|}
0.1 \\
\end{tabular} & 0.214 & $14.0 \quad(15.3)$ & $14.4 \quad(18.4)$ & \begin{tabular}{l|}
-0.1 \\
\end{tabular} & 0.347 \\
\hline \multicolumn{9}{|c|}{$\begin{array}{l}\text { Notes: The baseline period length is a fixed } 12 \text {-month period before the depression diagnosis date. Binary or categorical baseline demographics and clinical characteristics } \\
\text { were compared using McNemar's test, while continuous variables were compared using paired } t \text {-tests. All-cause health care resource use was compared using the nonpara- } \\
\text { metric Wilcoxon signed-rank test. A P value of }<0.05 \text { was considered a statistically significant difference. } \\
\text { aComorbid conditions used in PSM with a prevalence of }>5 \% \text { in either the matched TRD or non-TRD cohorts are included here. } \\
\text { bother includes home health care, hospice facility, inpatient rehab, outpatient psych, other location, other outpatient, skilled nursing facility, and surgical center. } \\
C C I=\text { Charlson Comorbidity Index; ED =emergency department; MSA = metropolitan statistical area; } N A=\text { not applicable; PSM=propensity score matching; SD =standard } \\
\text { deviation; TRD= treatment-resistant depression }\end{array}$} \\
\hline
\end{tabular}

obesity. Provider types in PSM included family medicine practitioner, psychiatrist, internist, and other types.

The goal of the study was to compare HCRU and payments among patients initiating third-line therapy for the TRD cohort to an appropriately chosen cohort of patients who did not initiate third-line therapy (non-TRD cohort). Since there was a time lag between the initiation of the second-line therapy and start of the third-line therapy among the TRD cohort, a similar time lag was generated to ensure that the comparison was meaningful.

To this effect, the PSM TRD and non-TRD cohorts were first exact matched on calendar quarter and year of the initiation of second-line therapy. Next, the mean time from the start of second-line to third-line initiation for the matched TRD cohort was added to the second-line initiation date for the exact-matched non-TRD cohort in order to generate the simulated index date for the non-TRD cohort. The intention of this simulation was to ensure that the simulated time lag represented the time lag when a similar non-TRD patient could have started third-line therapy. Finally, patients in the non-TRD cohort were required to have at least 12 months of continuous enrollment following the simulated index date. If this criterion was not met for the non-TRD cohort, both matched case (TRD cohort) and control (non-TRD cohort) were dropped from the analysis.

\section{Study Outcomes}

During the 12-month follow-up period, all-cause and depression-related HCRU and associated health care payments were estimated for TRD and non-TRD cohorts. The total number of all-cause and depression-related HCRU events was assessed and reported by type of service (i.e., hospitalization, emergency department [ED] visit, outpatient visit, and other visit) and 
pharmacy use. Other visits consisted of home health care visits, hospice facility stays, inpatient rehabilitation stays, outpatient psychiatric visits, other outpatient visits, skilled nursing facility (SNF) stays, and surgical center visits. A depressionrelated visit was defined as a medical claim with a primary or secondary depression-related diagnosis. Depression-related pharmacotherapy was defined as a prescription for a depression-related medication, including antidepressants (SSRIs, SNRIs, norepinephrine-dopamine reuptake inhibitors, tricyclics, tetracyclics, MAOIs, noradrenergic antagonist, and 5HT1, 5HT2, and 5HT3 receptor antagonists) and antipsychotics. Total health care payments were defined as the sum of payments associated with hospitalizations, ED visits, outpatient visits, other visits, and pharmacy use and were assessed from the payer perspective. Payments were measured as the amount reimbursed by the health care plan/payer and therefore did not include patient copayments and deductibles. Payments were inflated to 2016 U.S. dollars based on the medical care component of the Consumer Price Index information provided by the Bureau of Labor Statistics. ${ }^{23}$

\section{Data Analysis}

Descriptive analyses of all baseline and follow-up study measures included means and SDs, medians, interquartile ranges, minimums, and maximums for continuous measures and percentages for categorical/binary variables. Binary or categorical baseline demographics and clinical characteristics were compared using McNemar's test, while continuous variables were compared using paired t-tests. All-cause and depression-related HCRU and associated payments were compared between TRD and non-TRD cohorts using the nonparametric Wilcoxon signed-rank test. A $P$ value of $<0.05$ was considered a statistically significant difference. Sample selection and creation of analytic variables were performed using the Instant Health Data platform (Boston Health Economics, Boston, MA). Statistical analyses were performed using R, version 3.2.1 (R Foundation for Statistical Computing, Vienna, Austria).

\section{Results}

\section{Overview}

We identified 6,155,315 patients within the Truven Health MarketScan databases between October 1, 2009, and September 30, 2014, who had at least 1 depression diagnosis. Of those, 1,112 patients met patient selection criteria for the TRD cohort, and 10,734 patients met the criteria for the non-TRD cohort (Figure 1).

\section{Baseline Demographic and Clinical Characteristics}

Unmatched TRD and Non-TRD Cohorts. Patients in the TRD cohort were significantly younger than the non-TRD cohort (38.8 years vs. 40.1 years; $P=0.019$ ) and consisted of a significantly higher proportion of patients residing in an MSA
(86.5\% vs. $83.7 \% ; P=0.014)$. Differences in geographic region were also statistically significant $(P=0.007)$, with more patients in the TRD cohort residing in the South and Midwest regions compared with the non-TRD cohort. Also, compared with the non-TRD cohort, patients in the TRD cohort had significantly higher rates of anxiety disorder diagnoses (11.9\% vs. 10.0\%; $P=0.048)$. Differences in provider type were also statistically significant $(P<0.001)$, with more patients in the TRD cohort diagnosed by a psychiatrist compared with the non-TRD cohort (Table 1). In the TRD cohort, the mean (SD) time from first-line treatment initiation to the TRD index date was 246.5 days (69.3) (median=249.5), while the mean (SD) time from second-line treatment initiation to the TRD index date was 122.4 days $(61.0$; median $=112)$.

Matched TRD and Non-TRD Cohorts. The matching process yielded well-balanced cohorts, with no statistical differences in the baseline covariates (demographic, clinical, and all-cause HCRU; Table 1). The propensity score distribution yielded the following mean (SD) scores: unmatched TRD cohort $=0.101(0.031)$, unmatched non-TRD cohort $=0.094$ (0.025), matched TRD cohort $=0.101$ (0.025), and matched non-TRD cohort $=0.101(0.025)$. The matched analysis included 800 patients in the TRD and non-TRD cohorts. Following matching, approximately $60 \%$ of patients were female, and mean (SD) ages were 38.6 (14.2) and 39.3 (15.0) years for the TRD and non-TRD cohorts, respectively. Pain, anxiety disorder, cardiovascular disease, and obesity were the most common comorbid conditions identified in the matched study populations (Table 1).

\section{Treatment Patterns Among Matched Cohorts}

The mean (SD) durations of first- and second-line therapies among the matched TRD cohort were 105.5 (55.1) and 106.7 (54.3) days, respectively, which were both shorter than the mean (SD) durations among the matched non-TRD cohort (first line $=122.0$ [68.3]; second line $=169.2$ [82.4] days).

Among the matched TRD cohort, the most frequently used first-line class of treatments included SSRIs (82.0\%); however, that proportion declined in second and third lines $(61.9 \%$ and $56.1 \%$, respectively), with increasing proportions of bupropion (dopamine reuptake blocker) use in second and third lines (28.9\% and $36.1 \%$, respectively, compared with $11.0 \%$ in first line). Frequently used third-line treatments for the TRD cohort included SSRIs (56.1\%), dopamine reuptake blockers (36.1\%), SNRIs (31.4\%), and antipsychotics (14.0\%). Similar trends were observed for first- and second-line classes of treatment among the matched non-TRD cohort. The most frequently used firstline class of treatments included SSRIs (77.9\%); however, that proportion declined in second line (65.8\%), with an increasing proportion of bupropion use in second line (33.1\% compared with $12.6 \%$ in first line). Patients may have been prescribed 
$\geq 1$ depression diagnosis ( $\geq 1$ inpatient admission or $\geq 2$ outpatient visits with a primary or secondary depression diagnosis between October 1, 2009, and September 30, 2014; i.e., depression diagnosis date)

$$
\mathrm{N}=6,155,315
$$

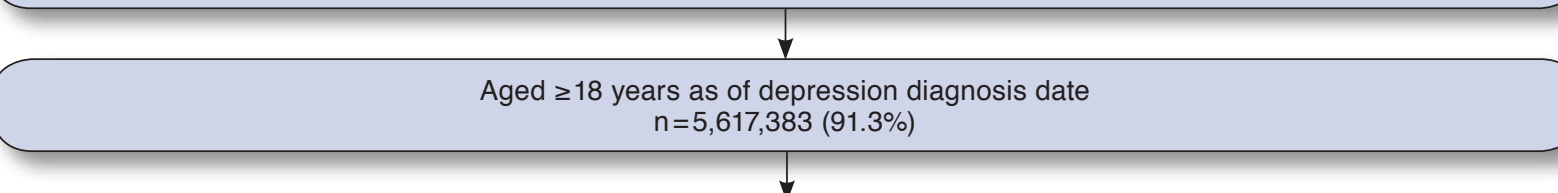

Received an initial antidepressant $\leq 14$ days following depression diagnosis date (defined as first-line therapy; date of first prescription defined as first-line index date) for $\geq 44$ days within 2 consecutive 30 -day segments

$$
n=1,196,769(21.3 \%)
$$

Received a different antidepressant in the same or different class than first-line therapy, or augmented first-line therapy with a different antidepressant or a second-generation antipsychotic in 360 days following first-line therapy, and treated for $\geq 44$ days within 2 consecutive 30 -day segments (defined as second-line therapy)

$$
\mathrm{n}=186,533(15.6 \%)
$$

Received a different antidepressant in the same or different class than first- and second-line therapies, or augmented second-line therapy with a different antidepressant or a different second-generation antipsychotic in 360 days following first-line therapy (defined as third-line therapy; date of initiation of third-line therapy defined as the TRD index date) $n=27,615(14.8 \%)$

Continuous medical and pharmacy benefits enrollment in 12 months before depression diagnosis date through 12 months after the TRD index date (for TRD cohort only)

$$
n=10,833(39.2 \%)
$$

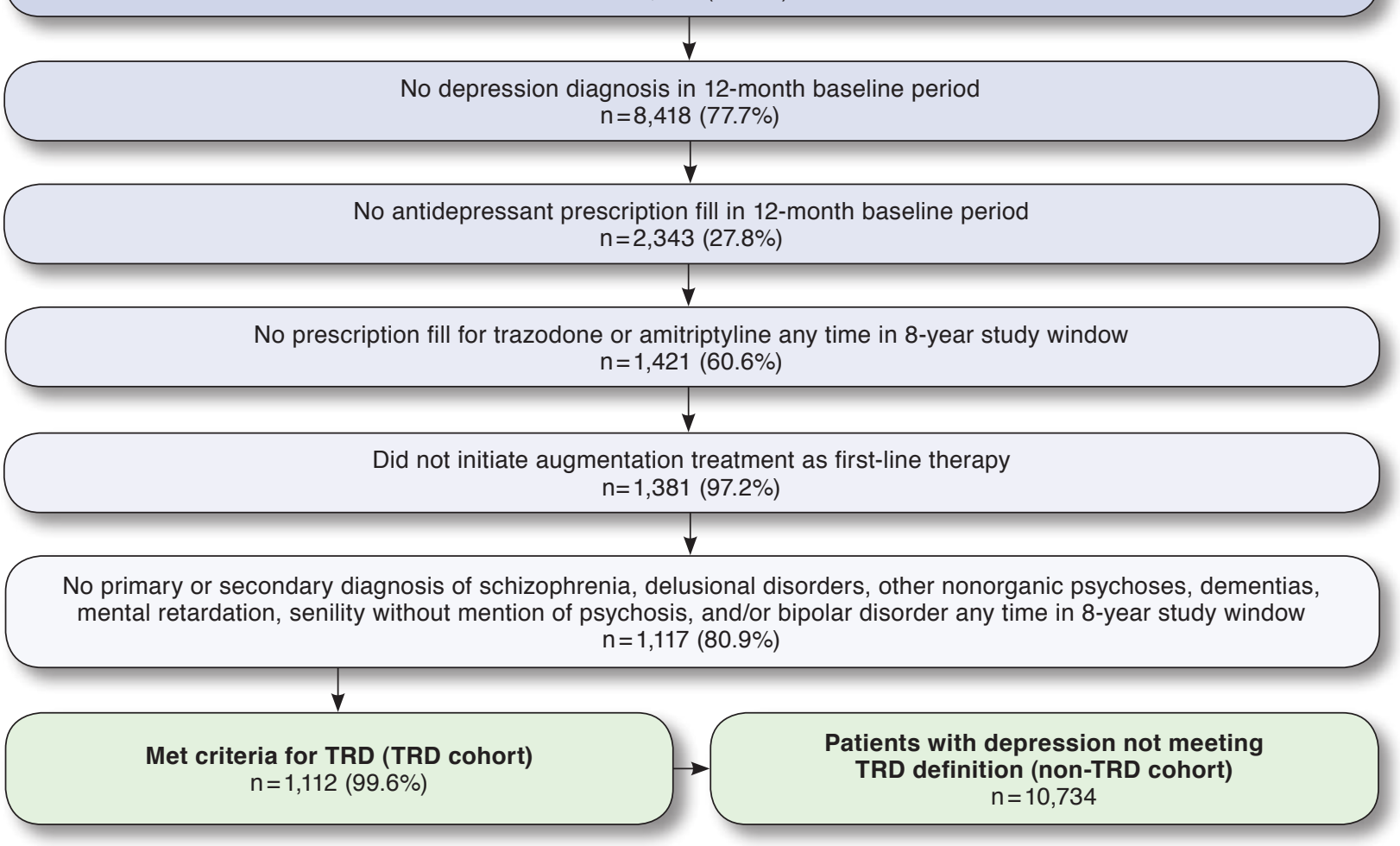

$T R D=$ treatment-resistant depression 


\begin{tabular}{|c|c|c|c|c|c|}
\hline & \multicolumn{3}{|c|}{ TRD } & \multicolumn{2}{|c|}{ Non-TRD } \\
\hline & First Line & Second Line & Third Line & First Line & Second Line \\
\hline \multicolumn{6}{|l|}{ Most common therapies, by drug class, $\mathrm{n}(\%)$} \\
\hline SSRI & $656(82.0)$ & $495(61.9)$ & $449(56.1)$ & $623(77.9)$ & $526(65.8)$ \\
\hline SNRI & $41 \quad(5.1)$ & $175(21.9)$ & $251(31.4)$ & $54 \quad(6.8)$ & $155(19.4)$ \\
\hline Dopamine reuptake blocker & $88(11.0)$ & $231(28.9)$ & $289(36.1)$ & $101(12.6)$ & $265(33.1)$ \\
\hline Tetracyclic & $10 \quad(1.2)$ & $21 \quad(2.6)$ & $42 \quad(5.3)$ & $16 \quad(2.0)$ & $19 \quad(2.4)$ \\
\hline Antipsychotic & $0 \quad(0.0)$ & $55 \quad(6.9)$ & $112(14.0)$ & $0 \quad(0.0)$ & $27 \quad(3.4)$ \\
\hline Other & $6 \quad(0.7)$ & $(4.4)$ & $57 \quad(7.1)$ & $6 \quad(0.8)$ & $27 \quad(3.4)$ \\
\hline \multicolumn{6}{|l|}{ Top 10 most common therapies, by drug, n (\%) } \\
\hline Citalopram (SSRI) & $187(23.4)$ & $65 \quad(8.1)$ & $(4.4)$ & $196(24.5)$ & $67 \quad(8.4)$ \\
\hline Sertraline (SSRI) & $169(21.1)$ & $78 \quad(9.8)$ & $(4.8)$ & $162(20.3)$ & $95(11.9)$ \\
\hline Escitalopram (SSRI) & $148(18.5)$ & $75 \quad(9.4)$ & $54 \quad(6.8)$ & $144(18.0)$ & $68 \quad(8.5)$ \\
\hline Fluoxetine (SSRI) & $119(14.9)$ & $56 \quad(7.0)$ & $(5.6)$ & $90(11.3)$ & $67 \quad(8.4)$ \\
\hline Bupropion (dopamine reuptake blocker) & $88(11.0)$ & $98(12.3)$ & $(8.4)$ & $101(12.6)$ & $102(12.8)$ \\
\hline Paroxetine (SSRI) & $30 \quad(3.8)$ & & & $31 \quad(3.9)$ & \\
\hline Venlafaxine (SNRI) & $21 \quad(2.6)$ & $76 \quad(9.5)$ & $(6.9)$ & (3.3) & $62 \quad(7.8)$ \\
\hline Duloxetine (SNRI) & 13 (1.6) & $49 \quad(6.1)$ & $41 \quad(5.1)$ & $18 \quad(2.3)$ & $43 \quad(5.4)$ \\
\hline Mirtazapine (tetracyclic) & $10 \quad(1.3)$ & & & $16 \quad(2.0)$ & \\
\hline Desvenlafaxine (SNRI) & $7 \quad(0.9)$ & & & $10 \quad(1.3)$ & \\
\hline Bupropion + sertraline (dopamine reuptake blocker+SSRI) & & $36 \quad(4.5)$ & $27 \quad(3.4)$ & & $36 \quad(4.5)$ \\
\hline Bupropion + citalopram (dopamine reuptake blocker + SSRI) & & $27 \quad(3.4)$ & & & $35 \quad(4.4)$ \\
\hline Bupropion + escitalopram (dopamine reuptake blocker + SSRI) & & $(3.3)$ & $(3.5)$ & & $38 \quad(4.8)$ \\
\hline Bupropion + fluoxetine (dopamine reuptake blocker+SSRI) & & & (3.6) & & \\
\hline
\end{tabular}

augmentation therapy during second and third lines, thus resulting in proportions of therapy classes summing to more than $100 \%$. The distribution of the top 10 most common depression therapies for the matched TRD and non-TRD cohorts are presented in Table 2.

\section{Annual HCRU and Payments During the 12-Month Follow-up Among Matched Cohorts}

The annual mean (SD) number of all-cause ED visits, outpatient visits, and prescriptions filled were all significantly greater for the matched TRD cohort than the non-TRD cohort $($ ED visits $=0.29$ [0.86] vs. 0.24 [0.82]; outpatient visits $=17.96$ [16.95] vs. 13.39 [13.93]; prescriptions filled=29.86 [25.03] vs. 23.99 [22.25]; all $P<0.05)$. The difference in the number of all-cause hospitalizations between the 2 cohorts was not significant (Table 3). Annual mean (SD) total all-cause payments were significantly higher for the TRD cohort than the non-TRD cohort $(\$ 9,890[\$ 36,278]$ vs. $\$ 6,848[\$ 17,297] ; P<0.001)$, a difference of more than $\$ 3,000$ in mean all-cause costs that represents the annual financial burden attributable to TRD. The TRD cohort had significantly higher annual mean all-cause ED, outpatient, and pharmacy payments (all $P<0.05$; Appendix B, available in online article).
The annual mean (SD) numbers of depression-related hospitalizations, ED visits, outpatient visits, and prescriptions filled were significantly greater for the matched TRD cohort than the non-TRD cohort (hospitalizations $=0.04[0.21]$ vs. $0.02[0.18]$; $\mathrm{ED}$ visits $=0.04[0.21]$ vs. $0.02[0.15]$; outpatient visits $=6.47$ [10.89] vs. 3.24 [7.27]; prescriptions filled $=10.12$ [7.02] vs. 6.54 [5.92]; all $P<0.05$; Table 3). The annual mean (SD) total depression-related payments were significantly higher for the TRD cohort than the non-TRD cohort $(\$ 2,740[\$ 8,916]$ vs. $\$ 1,322$ [\$7,193]; $P<0.001$ ). The TRD cohort had significantly higher annual mean depression-related inpatient, ED, outpatient, and pharmacy payments (all $P<0.05$; Appendix B).

\section{Comparison of TRD Identification Across Published Studies}

The secondary objective of this study was to compare the current methodology with other published studies that reported the economic burden of TRD.

Observation Period. The definition of the observation period, during which HCRU and associated payments were measured, differed between our study and the published literature. A few studies estimated HCRU and costs during the same 2-year period in which TRD patients were identified. ${ }^{8,10,16}$ Using this approach, some patients may not have been identified 


\begin{tabular}{|c|c|c|c|c|c|c|c|}
\hline \multirow[b]{2}{*}{ Resource } & \multicolumn{3}{|c|}{$\operatorname{TRD}(n=800)$} & \multicolumn{3}{|c|}{ Non-TRD $(n=800)$} & \multirow[b]{2}{*}{$P$ Value } \\
\hline & Mean & SD & Median & Mean & SD & Median & \\
\hline \multicolumn{8}{|c|}{ All-cause resource utilization } \\
\hline Hospitalizations & 0.08 & 0.37 & 0.00 & 0.09 & 0.35 & 0.00 & 0.418 \\
\hline ED visits & 0.29 & 0.86 & 0.00 & 0.24 & 0.82 & 0.00 & 0.047 \\
\hline Outpatient visits & 17.96 & 16.95 & 13.00 & 13.39 & 13.93 & 8.50 & $<0.001$ \\
\hline Other visits ${ }^{\mathrm{a}}$ & 1.72 & 6.89 & 0.00 & 1.90 & 10.82 & 0.00 & 0.072 \\
\hline Prescriptions & 29.86 & 25.03 & 23.00 & 23.99 & 22.25 & 18.00 & $<0.001$ \\
\hline \multicolumn{8}{|c|}{ Depression-related resource utilization } \\
\hline Hospitalizations & 0.04 & 0.21 & 0.00 & 0.02 & 0.18 & 0.00 & 0.031 \\
\hline ED visits & 0.04 & 0.21 & 0.00 & 0.02 & 0.15 & 0.00 & 0.013 \\
\hline Outpatient visits & 6.47 & 10.89 & 3.00 & 3.24 & 7.27 & 1.00 & $<0.001$ \\
\hline Other visits ${ }^{\mathrm{a}}$ & 0.18 & 2.23 & 0.00 & 0.07 & 0.66 & 0.00 & 0.409 \\
\hline Prescriptions & 10.12 & 7.02 & 9.00 & 6.54 & 5.92 & 5.00 & $<0.001$ \\
\hline \multicolumn{8}{|c|}{$\begin{array}{l}\text { Notes: The follow-up period was defined as (a) the 12-month period following the TRD index date for the TRD cohort, and (b) the 12-month period following a simula } \\
\text { index date for the non-TRD cohort. All-cause and depression-related HCRU were compared using nonparametric Wilcoxon signed-rank tests. A P value of }<0.05 \text { was } \\
\text { considered a statistically significant difference. } \\
\text { aOther includes home health care, hospice facility, inpatient rehab, outpatient psych, other location, other outpatient, skilled nursing facility, and surgical center. } \\
\text { ED=emergency department; HCRU = health care resource utilization; } S D=\text { standard deviation; TRD = treatment-resistant depression. }\end{array}$} \\
\hline
\end{tabular}

as TRD cases until the end of the 2-year observation period, which would not allow for a distinction between pre-TRD and post-TRD costs. Other studies assessed HCRU and cost consequences of developing TRD in an adjacent 12-month period following a TRD identification period. ${ }^{9,11}$ More specifically, these studies identified TRD patients during an initial 12-month period and assessed outcomes in a subsequent (i.e., adjacent) 12-month period. Using this approach, some patients may have been identified as TRD cases during the first half of the TRD identification period, which would not allow for an assessment of the immediate effect of TRD on outcomes. In contrast, our study analyzed health care payments in the 12-month period following initiation of third-line therapy, a unique approach in that post-TRD annual costs were assessed independently of pre-TRD costs (Table 4).

TRD Case Selection. The majority of published studies, including our study, used a claims-based algorithm for defining TRD cases, which was based on the number of failed courses of depression therapy of adequate duration. ${ }^{8-10,16,17,19}$ Most studies required TRD patients to have failed at least 2 regimens of depression therapy of at least 6 weeks duration, which was similar to the methodology applied to our study. Additionally, some studies required adequate dosing for depression therapy $8,9,16,17,19$; however, our methods did not consider adequate dosing given the common occurrence of dose adjustments for many antidepressants.

Other studies used scale and matrix criteria to classify patients as TRD-likely. ${ }^{12,16,18}$ The TRD scale was constructed based on specific depression therapies received, the number of switches among antidepressants relative to the switching patterns of all patients, and the number of upward titrations of an antidepressant relative to all patients receiving antidepressants. Patients with a score of 5 were considered to be TRDlikely. The TRD matrix required that patients receive at least 3 switches or at least 2 switches and 2 upward titrations of antidepressants to be considered TRD-likely. Patients meeting both scale and matrix criteria were classified as TRD-likely. Patients receiving ECT or MAOIs any time during the study period were automatically classified as TRD-likely.

Gibson et al. (2010) used a third methodology to assign patients to the TRD or non-TRD cohorts. ${ }^{11}$ The authors used the Massachusetts General Hospital antidepressant only score, assigning 1 point for each adequate antidepressant trial, half a point for each optimization strategy, and 3 points for any use of ECT. A patient with a score $\geq 3$ was classified as having TRD.

Propensity Score Matching. In randomized clinical trials, patients are prospectively randomized into study groups where each participant has an equal chance of being assigned to each group. As a result, selection bias and confounding are minimized because the likelihood of receiving the treatment is equal. However, in retrospective, real-world database studies, researchers are unable to randomly assign patients to treatment options because the treatment selection already occurred.

PSM is a useful technique that can be used with real-world health care data when randomization is impossible or unethical. PSM allows researchers to more closely estimate the true effect of an intervention-or in this study's design-the true effect of receiving third-line therapy by decreasing sampling 


\begin{tabular}{|c|c|c|c|c|c|c|c|c|c|c|c|}
\hline \multirow[b]{2}{*}{$\begin{array}{l}\text { Author/ } \\
\text { Year }\end{array}$} & \multirow[b]{2}{*}{$\begin{array}{l}\text { Analysis } \\
\text { Period }\end{array}$} & \multirow[b]{2}{*}{$\begin{array}{l}\text { Index } \\
\text { Date }\end{array}$} & \multirow[b]{2}{*}{$\begin{array}{c}\text { ICD-9-CM } \\
\text { Diagnosis } \\
\text { Codes to } \\
\text { Identify MDD }\end{array}$} & \multicolumn{6}{|c|}{ TRD Case Definition } & \multirow[b]{2}{*}{$\begin{array}{c}\text { Observation } \\
\text { Period } \\
\text { Definition }\end{array}$} & \multirow[b]{2}{*}{$\begin{array}{c}\text { Multivariate } \\
\text { Analysis }\end{array}$} \\
\hline & & & & $\begin{array}{l}\text { TRD ID } \\
\text { Period }\end{array}$ & $\begin{array}{l}\text { Number } \\
\text { of Failed } \\
\text { Courses of } \\
\text { Depression } \\
\text { Therapy } \\
\end{array}$ & $\begin{array}{l}\text { Adequate } \\
\text { Duration }\end{array}$ & $\begin{array}{c}\text { Adequate } \\
\text { Dose }\end{array}$ & $\begin{array}{c}\text { TRD } \\
\text { Scale and } \\
\text { Matrix } \\
\text { Criteria } \\
\end{array}$ & $\begin{array}{l}\text { MGH } \\
\text { TRD } \\
\text { Staging } \\
\text { Method }\end{array}$ & & \\
\hline $\begin{array}{l}\text { Current } \\
\text { approach }\end{array}$ & $\begin{array}{c}\text { 10/2008- } \\
\text { 9/2016 }\end{array}$ & \begin{tabular}{|c|} 
TRD cohort: \\
Third-line \\
initiation \\
Non-TRD \\
cohort: \\
Simulated \\
index date \\
based on the \\
TRD cohort's \\
third-line \\
initiation date \\
\end{tabular} & \begin{tabular}{|c|}
$296.2 x$ \\
$296.3 x$ \\
$300.4,309.0$ \\
309.1, or 311 \\
\end{tabular} & \begin{tabular}{|c|} 
A variable \\
period of \\
$\leq 360$ days \\
following \\
first-line \\
antidepressant \\
initiation
\end{tabular} & $\geq 2$ & $\begin{array}{l}\geq 44 \text { days } \\
\text { within } 2 \\
\text { consecutive } \\
30 \text {-day } \\
\text { segments }\end{array}$ & & & & $\begin{array}{c}\text { 12-month } \\
\text { period } \\
\text { following } \\
\text { index date }\end{array}$ & PSM \\
\hline $\begin{array}{l}\text { Amos } \\
2018^{8}\end{array}$ & $\begin{array}{c}\text { 7/2009- } \\
3 / 2015\end{array}$ & \begin{tabular}{|c|} 
First \\
observed \\
antidepressant \\
that occurred \\
after $\geq 6$ \\
months \\
without an \\
antidepressant \\
\end{tabular} & \begin{tabular}{|c|}
$296.2 \mathrm{x}$ or \\
$296.3 \mathrm{x}$ \\
and \\
$296.2 \mathrm{x}$ \\
$296.3 \mathrm{x}$ \\
$300.4 \mathrm{x}, 311 . \mathrm{x}$, \\
$309.0 \mathrm{x}$ \\
or $309.1 \mathrm{x}$ \\
at least 6 \\
months \\
before or after \\
the antide- \\
pressant fill \\
date \\
starting \\
January 2010
\end{tabular} & \begin{tabular}{|} 
Index date \\
to the \\
earliest of \\
2 years \\
following the \\
first \\
antidepressant, \\
end of \\
continuous \\
eligibility, or \\
end of data \\
availability \\
\end{tabular} & $\geq 2$ & $\begin{array}{l}\geq 6 \text { weeks } \\
\text { without } \\
\text { gaps of } \\
\text { longer than } \\
14 \text { days }\end{array}$ & $\checkmark$ & & & $\begin{array}{l}\text { Same as } \\
\text { TRD ID } \\
\text { period }\end{array}$ & $\begin{array}{l}\text { PSM (TRD } \\
\text { vs. non-TRD } \\
\text { MDD; TRD } \\
\text { vs. no MDD) } \\
\text { OLS } \\
\text { regression } \\
\text { to estimate } \\
\text { adjusted } \\
\text { costs }\end{array}$ \\
\hline $\begin{array}{l}\text { Olfson } \\
2018^{9}\end{array}$ & $\begin{array}{l}1 / 2008- \\
7 / 2014\end{array}$ & \begin{tabular}{|c} 
First \\
observed \\
antidepressant \\
that occurred \\
after $\geq 6$ \\
months \\
without an \\
antidepressant \\
\end{tabular} & $\begin{array}{c}296.2,296.3, \\
300.4,311, \\
309.0 \text {, or } \\
309.1 \text { within } \\
30 \text { days } \\
\text { before or after } \\
\text { the index } \\
\text { antidepressant } \\
\text { prescription } \\
\text { fill } \\
\text { and } \\
\text { 296.2x or } \\
296.3 x \\
\text { during the } \\
12 \text { months } \\
\text { before or after } \\
\text { the index } \\
\text { antidepressant } \\
\text { fill }\end{array}$ & $\begin{array}{c}\text { First } \\
\text { 12-month } \\
\text { period } \\
\text { following the } \\
\text { index date } \\
\\
\end{array}$ & $\geq 2$ & $\begin{array}{l}\geq 6 \text { weeks } \\
\text { without } \\
\text { gaps of } \\
\text { longer than } \\
14 \text { days }\end{array}$ & $\sqrt{ }$ & & & $\begin{array}{l}\text { Adjacent } \\
\text { 12-month } \\
\text { period } \\
\text { following } \\
\text { the TRD ID } \\
\text { period }\end{array}$ & $\begin{array}{l}\text { 2-part model } \\
\text { to estimate } \\
\text { adjusted } \\
\text { costs (first } \\
\text { part: logistic } \\
\text { regression; } \\
\text { second part: } \\
\text { GLM with } \\
\text { gamma } \\
\text { distribution } \\
\text { and log link) }\end{array}$ \\
\hline $\begin{array}{l}\text { Olchanski } \\
2013^{10}\end{array}$ & $\begin{array}{l}1 / 2001- \\
12 / 2009\end{array}$ & Not specified & \begin{tabular}{|c|}
$296.2 x$ \\
$296.3 x$ \\
$300.4,309.0$ \\
$309.2 x$, or \\
311
\end{tabular} & \begin{tabular}{|} 
z2-year \\
period of \\
continuous \\
treatment for \\
MDD
\end{tabular} & $\geq 4$ & $\geq 12$ weeks & & & & $\begin{array}{l}\text { Same as } \\
\text { TRD ID } \\
\text { period }\end{array}$ & $\begin{array}{c}\text { Log-linear } \\
\text { regression } \\
\text { model to } \\
\text { estimate } \\
\text { adjusted costs }\end{array}$ \\
\hline $\begin{array}{l}\text { Ivanova } \\
2010^{16}\end{array}$ & $\begin{array}{l}1 / 1999- \\
12 / 2007\end{array}$ & \begin{tabular}{|c} 
First \\
observed \\
antidepressant \\
on or after \\
$1 / 1 / 2004$
\end{tabular} & $\begin{array}{c}296.2 \mathrm{x} \text { or } \\
296.3 \mathrm{x}\end{array}$ & $\begin{array}{c}\text { 2-year period } \\
\text { following the } \\
\text { index date }\end{array}$ & $\geq 2$ & $\geq 6$ weeks & $\checkmark$ & $\begin{array}{c}\boldsymbol{J} \\
\text { (alternative } \\
\text { approach) }\end{array}$ & & $\begin{array}{l}\text { Same as } \\
\text { TRD ID } \\
\text { period }\end{array}$ & $\begin{array}{c}\text { Matching } \\
\text { (type not } \\
\text { specified) } \\
\text { GLM to } \\
\text { estimate } \\
\text { adjusted costs }\end{array}$ \\
\hline
\end{tabular}




\section{TABLE 4 Methodological Comparisons to Currently Published Literature (continued)}

\begin{tabular}{|c|c|c|c|c|c|c|c|c|c|c|c|}
\hline \multirow[b]{2}{*}{$\begin{array}{l}\text { Author/ } \\
\text { Year }\end{array}$} & \multirow[b]{2}{*}{$\begin{array}{l}\text { Analysis } \\
\text { Period }\end{array}$} & \multirow[b]{2}{*}{$\begin{array}{l}\text { Index } \\
\text { Date }\end{array}$} & \multirow[b]{2}{*}{$\begin{array}{c}\text { ICD-9-CM } \\
\text { Diagnosis } \\
\text { Codes to } \\
\text { Identify MDD }\end{array}$} & \multicolumn{6}{|c|}{ TRD Case Definition } & \multirow[b]{2}{*}{$\begin{array}{l}\text { Observation } \\
\text { Period } \\
\text { Definition }\end{array}$} & \multirow[b]{2}{*}{$\begin{array}{c}\text { Multivariate } \\
\text { Analysis }\end{array}$} \\
\hline & & & & $\begin{array}{l}\text { TRD ID } \\
\text { Period }\end{array}$ & $\begin{array}{l}\text { Number } \\
\text { of Failed } \\
\text { Courses of } \\
\text { Depression } \\
\text { Therapy }\end{array}$ & $\begin{array}{l}\text { Adequate } \\
\text { Duration }\end{array}$ & $\begin{array}{c}\text { Adequate } \\
\text { Dose }\end{array}$ & $\begin{array}{c}\text { TRD } \\
\text { Scale and } \\
\text { Matrix } \\
\text { Criteria }\end{array}$ & $\begin{array}{c}\text { MGH } \\
\text { TRD } \\
\text { Staging } \\
\text { Method }\end{array}$ & & \\
\hline $\begin{array}{l}\text { Gibson } \\
2010^{11}\end{array}$ & $\begin{array}{l}1 / 2000- \\
12 / 2007\end{array}$ & $\begin{array}{c}\text { First } \\
\text { observed } \\
\text { antidepressant }\end{array}$ & \begin{tabular}{|c|}
$296.2 x$ \\
$296.3 x$ \\
$300.4,309.0$ \\
or 311
\end{tabular} & $\begin{array}{c}\text { 2-year period } \\
\text { following the } \\
\text { index date }\end{array}$ & & & & & $\checkmark$ & $\begin{array}{c}\text { Adjacent } \\
12 \text {-month } \\
\text { period } \\
\text { following } \\
\text { the TRD ID } \\
\text { period }\end{array}$ & $\begin{array}{c}\text { PSM } \\
\text { GLM to } \\
\text { estimate } \\
\text { adjusted } \\
\text { costs }\end{array}$ \\
\hline $\begin{array}{l}\text { Russell } \\
200417\end{array}$ & $\begin{array}{l}1 / 1995- \\
12 / 2000\end{array}$ & \begin{tabular}{|c|} 
Date patients \\
met all \\
criteria for \\
TRD \\
\end{tabular} & \begin{tabular}{|c|}
$296.2 \mathrm{x}$ \\
$296.3 \mathrm{x}$ \\
$296.5 \mathrm{x}$ \\
$296.6 \mathrm{x}$ \\
296.89 \\
$300.4,309.0$ \\
309.1, or 311
\end{tabular} & $\begin{array}{c}\text { Entire study } \\
\text { window }\end{array}$ & $\begin{array}{c}\geq 2 \text { or } \geq 1 \text { plus } \\
\text { a depression- } \\
\text { related } \\
\text { hospitalization, } \\
\text { ECT, or a } \\
\text { suicide } \\
\text { attempt }\end{array}$ & $\geq 4$ weeks & $\checkmark$ & & & $\begin{array}{l}\text { Index date } \\
\text { to the time } \\
\text { of each } \\
\text { subsequent } \\
\text { depression } \\
\text { medication } \\
\text { regimen } \\
\text { change }\end{array}$ & $\begin{array}{l}\text { Negative } \\
\text { binomial } \\
\text { regression } \\
\text { model to } \\
\text { estimate the } \\
\text { number of } \\
\text { antidepressant } \\
\text { regimen } \\
\text { changes }\end{array}$ \\
\hline $\begin{array}{l}\text { Greenberg } \\
200418\end{array}$ & $\begin{array}{l}1 / 1996- \\
12 / 1998\end{array}$ & Not specified & $\begin{array}{c}296.2 x \\
296.3 x \\
300.4,309.0 \\
309.2 x, \text { or } \\
311\end{array}$ & 1996-1998 & & & & $\checkmark$ & & 1998 & None \\
\hline $\begin{array}{l}\text { Corey-Lisle } \\
2002^{12}\end{array}$ & $\begin{array}{l}1 / 1996- \\
12 / 1998\end{array}$ & Not specified & $\begin{array}{c}296.2 x \\
296.3 x \\
300.4,309.0 \\
309.2 x, \text { or } \\
311\end{array}$ & 1996-1998 & & & & $\checkmark$ & & 1998 & None \\
\hline $\begin{array}{l}\text { Crown } \\
2002^{19}\end{array}$ & $\begin{array}{l}1 / 1995- \\
6 / 2000\end{array}$ & \begin{tabular}{|} 
Hospitalized \\
cohort: day \\
following \\
hospital dis- \\
charge and/ \\
or suicide \\
attempt \\
Outpatient \\
cohort: day \\
following the \\
dispensing of \\
the third \\
antidepressant
\end{tabular} & \begin{tabular}{|c|}
$296.2 \mathrm{x}$ \\
$296.3 \mathrm{x}$ \\
$296.5 \mathrm{x}$ \\
$296.6 \mathrm{x}$ \\
296.89 \\
$300.4,309.0$ \\
309.1, or 311 \\
\end{tabular} & $\begin{array}{c}\text { Time from } \\
\text { first } \\
\text { antidepressant } \\
\text { to the index } \\
\text { date }\end{array}$ & $\begin{array}{c}\text { Hospitalized } \\
\text { TRD cohort: } \\
\geq 1 \text { plus a } \\
\text { depression- } \\
\text { related } \\
\text { hospitaliza- } \\
\text { tion or } \\
\text { suicide } \\
\text { attempt } \\
\text { Outpatient } \\
\text { TRD cohort: } \\
\geq 2 \text { but were } \\
\text { not } \\
\text { hospitalized }\end{array}$ & $\geq 8$ weeks & $\checkmark$ & & & $\begin{array}{c}\text { Index date } \\
\text { through the } \\
\text { last } \\
\text { available } \\
\text { medical } \\
\text { claim } \\
(\geq 9 \text { months })\end{array}$ & $\begin{array}{l}\text { OLS } \\
\text { regression } \\
\text { to estimate } \\
\text { adjusted } \\
\text { costs }\end{array}$ \\
\hline
\end{tabular}

ECT=electroconvulsive therapy; GLM=generalized linear model; ICD-9-CM=International Classification of Diseases, Ninth Revision, Clinical Modification; $I D=i d e n t i f i c a t i o n ; M D D=$ major depressive disorder; $M G H=$ Massachusetts General Hospital; OLS=ordinary least squares; PSM=propensity score matching; $T R D=$ treatment-resistant depression

bias and inherent differences between study groups. ${ }^{24,25}$ The goal is to create comparable patients across cohorts. Only 2 published TRD studies, in addition to our study, employed PSM. ${ }^{8,11}$ In contrast, a number of studies conducted adjusted regression models (e.g., ordinary least squares regression model, generalized linear model with gamma distribution and log link) to estimate risk-adjusted direct medical costs (dependent variable). ${ }^{9,10,16,19}$ Two older studies did not conduct PSM or adjusted regression models (Table 4).12,18

\section{Discussion}

This retrospective analysis of administrative claims databases assessed HCRU and health care payments associated with TRD. Our findings suggest that the annual economic burden associated with TRD patients is higher than non-TRD patients following TRD identification. More specifically, mean allcause and depression-related total health care payments were approximately $\$ 3,000$ and $\$ 1,400$ higher, respectively, in the TRD cohort compared with the non-TRD cohort during the 
follow-up period. Significant drivers of this economic burden included differences in health care payments associated with ED visits, outpatient visits, and number of prescriptions. Additionally, annual all-cause direct medical payments associated with TRD $(\$ 9,890)$ are similar to patients with anxiety disorder but are less than financial payments among patients with either schizophrenia or bipolar 1 disorder. ${ }^{26-34}$

Similar to other recently published, retrospective claimsbased analyses, our findings suggest a significant economic

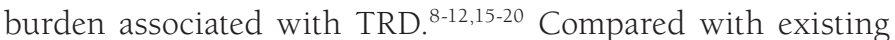
literature, our findings for annual all-cause health care payments associated with TRD $(\$ 3,042)$ appear to be more conservative. Some of the more recent claims-based analyses found excess annual all-cause health care costs associated with TRD to range between $\$ 6,000$ and $\$ 7,000$ (inflated to 2016 U.S. dollars), which is approximately twice the differential observed in our study. ${ }^{8,10,16}$ Additionally, 2 other claims-based studies using a treatment pattern-scoring algorithm found differences between the TRD and non-TRD cohorts of approximately $\$ 10,500$ and $\$ 14,000$ (inflated to 2016 U.S. dollars), which is 3 to 4 times the differential observed in our study. ${ }^{12,18}$ Differences in the literature may be a result of many factors, including (a) variations in definitions of the observation periods ${ }^{8-11}$; (b) alternative methods for identifying TRD cases $^{11,12,16,18,19}$; (c) the use of older data before the advent of newer antipsychotic therapies (e.g., brexpiprazole, quetiapine extended release, olanzapine plus fluoxetine) for the treatment of $\mathrm{MDD}^{12,18}$; and (d) analysis of a Medicaid-only population. ${ }^{9}$

\section{Limitations}

Our analyses are subject to certain limitations. To begin, there are inherent limitations when using a large retrospective claims database; claims data are subject to coding inaccuracies or inaccurate diagnoses. ${ }^{35}$ Additionally, claims data lack long-term historical and clinical information, which limits our ability to clinically identify disease history, disease severity, and treatment response.

Beyond the limitations in using claims data, other information gaps created limitations in defining our cohorts. While our definition of TRD included common components of adequate treatment duration and number of failed therapies used in other studies, it did not consider adequate medication dosing, since dose adjustments may have resulted in a conservative bias of our service utilization and cost estimates by defining some patients as having TRD who had not received adequate medication dosing.

By requiring continuous treatment with an antidepressant, we attempted to prohibit discontinuing or switching treatments due to adverse events. Through this process, some of the uncertainty inherent in claims data regarding the motivations for discontinuation or switching was reduced; however, the reasons why a patient discontinued or switched treatments were still not known. Therefore, a switch or discontinuation may not reflect treatment resistance (e.g., in the case of high out-of-pocket costs). Also, the non-TRD cohort may have included a mix of patients who either (a) continued secondline therapy or (b) discontinued second-line therapy without initiating third-line therapy during the treatment identification period, thereby creating a heterogeneous comparison cohort.

We did not include psychotherapy as one of the treatment options for depression in this study, which could limit our study findings. Furthermore, our analyses considered direct medical costs only and did not consider indirect costs such as productivity losses to the patient and caregiver, which were not available in the dataset. It is well documented that mental health disorders are associated with a significant indirect cost burden; by not considering indirect costs, our analysis underestimates the total economic burden of TRD.

\section{Conclusions}

In this study, we estimated the economic burden associated with TRD from a health plan perspective. Although previous studies provide insight into the economic burden associated with TRD patients, few published studies estimate costs directly following the initiation of third-line pharmacotherapy. According to results from the STAR*D trial, the remission rate falls with each failed line of depression therapy, with the most dramatic reduction occurring following the failure of 2 previous lines of therapy.

In addition to this clinical burden, the results from our study indicate that HCRU and associated payments are also higher for patients with depression who fail 2 previous lines of pharmacotherapy, thus highlighting an unmet economic need in this subpopulation of patients with depression. Improved and more effective management of these patients, either before progression to TRD through tests that improve the efficacy of and adherence to earlier lines of therapy or following progression to TRD through more efficacious third-line pharmacotherapies, may help reduce the economic burden of disease.

\section{Authors}

MATTHEW SUSSMAN, MA, and JOSEPH MENZIN, PhD, Boston Health Economics, Boston, Massachusetts. AMY K. O'SULLIVAN, PhD, and ANKIT SHAH, MS, Alkermes, Waltham, Massachusetts MARK OLFSON, MD, MPH, Columbia University Medical Center, New York, New York.

AUTHOR CORRESPONDENCE: Matthew Sussman, MA, Head of Modeling E Evidence Services, Boston Health Economics, 265 Franklin St., Ste. 1101, Boston, MA 02110. Tel.: 781.290.0808 x052; E-mail:msussman@bhei.com. 


\section{DISCLOSURES}

This study was funded by Alkermes. Sussman and Menzin, employees of Boston Health Economics, were paid consultants, and Olfson, an employee of Columbia University Irving Medical Center, was an unpaid consultant to Alkermes in connection with the study and development of this research article. O'Sullivan and Shah are employees of the study sponsor.

Results from this analysis were first presented at the AMCP Managed Care \& Specialty Pharmacy Annual Meeting in Boston, MA, on April 23-26, 2018.

\section{REFERENCES}

1. Hasin DS, Sarvet AL, Meyers JL, et al. Epidemiology of adult DSM-5 major depressive disorder and its specifiers in the United States. JAMA Psychiatry. 2018;75(4):336

2. Greenberg PE, Fournier A-A, Sisitsky T, Pike CT, Kessler RC. The economic burden of adults with major depressive disorder in the United States (2005 and 2010). J Clin Psychiatry. 2015;76(2):155-62.

3. Gartlehner G, Hansen RA, Morgan LC, et al. Comparative benefits and harms of second-generation antidepressants for treating major depressive disorder: an updated meta-analysis. Ann Intern Med. 2011;155(11):772-85.

4. Gelenberg AJ, Freeman MP, Markowitz JC, et al. Practice guideline for the treatment of patients with major depressive disorder. American Psychiatric Association. 2010. Available at: https://psychiatryonline.org/pb/assets/raw/ sitewide/practice_guidelines/guidelines/mdd.pdf. Accessed May 14, 2019.

5. Berlim MT, Turecki G. Definition, assessment, and staging of treatmentresistant refractory major depression: a review of current concepts and methods. Can J Psychiatry Rev Can Psychiatr. 2007;52(1):46-54.

6. Harald B, Gordon P. Meta-review of depressive subtyping models. J Affect Disord. 2012;139(2):126-40.

7. Gaynes BN, Asher G, Gartlehner G, et al. Definition of treatmentresistant depression in the Medicare population. Technology Assessment Project ID: PSYT0816. Agency for Healthcare Research and Quality. February 9, 2018. Available at: https://www.cms.gov/Medicare/Coverage/ DeterminationProcess/downloads/id105TA.pdf. Accessed May 31, 2019.

8. Amos TB, Tandon N, Lefebvre P, et al. Direct and indirect cost burden and change of employment status in treatment-resistant depression: a matched-cohort study using a US commercial claims database. J Clin Psychiatry. 2018;79(2).

9. Olfson M, Amos TB, Benson C, McRae J, Marcus SC. Prospective service use and health care costs of Medicaid beneficiaries with treatment-resistant depression. J Manag Care Spec Pharm. 2018;24(3):226-36. Available at: https://www.jmcp.org/doi/full/10.18553/jmcp.2018.24.3.226.

10. Olchanski N, McInnis Myers M, Halseth M, et al. The economic burden of treatment-resistant depression. Clin Ther. 2013;35(4):512-22.

11. Gibson TB, Jing Y, Smith Carls G, et al. Cost burden of treatment resistance in patients with depression. Am J Manag Care. 2010;16(5):370-77.

12. Corey-Lisle PK, Birnbaum HG, Greenberg PE, Marynchenko MB, Claxton AJ. Identification of a claims data "signature" and economic consequences for treatment-resistant depression. J Clin Psychiatry. 2002; 63(8):717-26

13. Rush AJ, Trivedi MH, Wisniewski SR, et al. Acute and longer-term outcomes in depressed outpatients requiring one or several treatment steps: a STAR*D report. Am J Psychiatry. 2006;163(11):1905-17.

14. Mrazek DA, Hornberger JC, Altar CA, Degtiar I. A review of the clinical, economic, and societal burden of treatment-resistant depression: 1996-2013 Psychiatr Serv. 2014;65(8):977-87.

15. Kubitz N, Mehra M, Potluri RC, Garg N, Cossrow N. Characterization of treatment resistant depression episodes in a cohort of patients from a U.S. commercial claims database. PloS One. 2013;8(10):e76882.

16. Ivanova JI, Birnbaum HG, Kidolezi Y, Subramanian G, Khan SA, Stensland MD. Direct and indirect costs of employees with treatmentresistant and non-treatment-resistant major depressive disorder. Curr Med Res Opin. 2010;26(10):2475-84.
17. Russell JM, Hawkins K, Ozminkowski RJ, et al. The cost consequences of treatment-resistant depression. J Clin Psychiatry. 2004;65(3):341-47.

18. Greenberg P, Corey-Lisle PK, Birnbaum H, Marynchenko M, Claxton A. Economic implications of treatment-resistant depression among employees. PharmacoEconomics. 2004:22(6):363-73.

19. Crown WH, Finkelstein S, Berndt ER, et al. The impact of treatmentresistant depression on health care utilization and costs. J Clin Psychiatry. 2002;63(11):963-71.

20. Lepine BA, Moreno RA, Campos RN, Couttolenc BF. Treatment-resistant depression increases health costs and resource utilization. Rev Bras Psiquiatr Sao Paulo Braz. 1999. 2012;34(4):379-88.

21. Segel J. Cost-of-illness studies-a primer. RTI-UNC Center of Excellence in Health Promotion Economics. 2006. Available at: https://pdfs.semanticscholar.org/3bbf/0a03079715556ad816a25ae9bf232b45f2e6.pdf. Accessed May 14, 2019.

22. Hansen L. The Truven Health MarketScan Databases for life sciences researchers. Truven Health Analytics. 2017. Available at: https://truvenhealth.com/Portals/0/Assets/2017-MarketScan-Databases-Life-SciencesResearchers-WP.pdf. Accessed May 14, 2019.

23. Bureau of Labor Statistics. Databases, tables \& calculators by subject. Available at: https://data.bls.gov/timeseries/CUUR0000SA0L1E?output_ view=pct_12mths. Accessed May 14, 2019.

24. Rosenbaum P, Rubin D. The central role of the propensity score in observational studies for causal effects. Biometrika. 1983;70(1):41-55.

25. Rosenbaum P, Donald R. Reducing bias in observational studies using subclassification on the propensity score. 1984;79(387):516-24.

26. Huang A, Amos T, Kruti J, Li W, Abigail N. Burden of schizophrenia in recently diagnosed adult patients: a commercial payer perspective. Presented at: The 30th Annual Psych Congress; September 16-19, 2017; New Orleans, LA. Available at: https://www.psychcongress.com/posters/burden-schizophrenia-recently-diagnosed-adult-patients-commercial-payer-perspective. Accessed May 14, 2019.

27. Fitch K, Iwasaki K, Villa K. Resource utilization and cost in a commercially insured population with schizophrenia. Am Health Drug Benefits. 2014;7(1):18-26.

28. Shirneshan E. Cost of illness study of anxiety disorders for the ambulatory adult population of the United States. University of Tennessee Health Science Center. 2013. Available at: https://dc.uthsc.edu/cgi/viewcontent.cgi?a rticle $=1370 \&$ context=dissertations. Accessed May 14, 2019.

29. Broder MS, Greene M, Chang E, et al. Health care resource use, costs, and diagnosis patterns in patients with schizophrenia and bipolar disorder: realworld evidence from U.S. claims databases. Clin Ther. 2018;40(10):1670-82.

30. Revicki DA, Travers K, Wyrwich KW, et al. Humanistic and economic burden of generalized anxiety disorder in North America and Europe. J Affect Disord. 2012;140(2):103-12.

31. Hoffman DL, Dukes EM, Wittchen H-U. Human and economic burden of generalized anxiety disorder. Depress Anxiety. 2008;25(1):72-90.

32. Wallace K, Zhao X, Misra R, Sambamoorthi U. The humanistic and economic burden associated with anxiety and depression among adults with comorbid diabetes and hypertension. J Diabetes Res. 2018;2018:1-9.

33. Cloutier M, Greene M, Guerin A, Touya M, Wu E. The economic burden of bipolar I disorder in the United States in 2015. J Affect Disord. 2018;226:45-51.

34. Williams MD, Shah ND, Wagie AE, Wood DL, Frye MA. Direct costs of bipolar disorder versus other chronic conditions: an employer-based health plan analysis. Psychiatr Serv. 2011;62(9):1073-78.

35. Schneeweiss S, Avorn J. A review of uses of health care utilization databases for epidemiologic research on therapeutics. J Clin Epidemiol. 2005;58(4):323-37. 


\section{APPENDIX A TRD Patient Timeline}

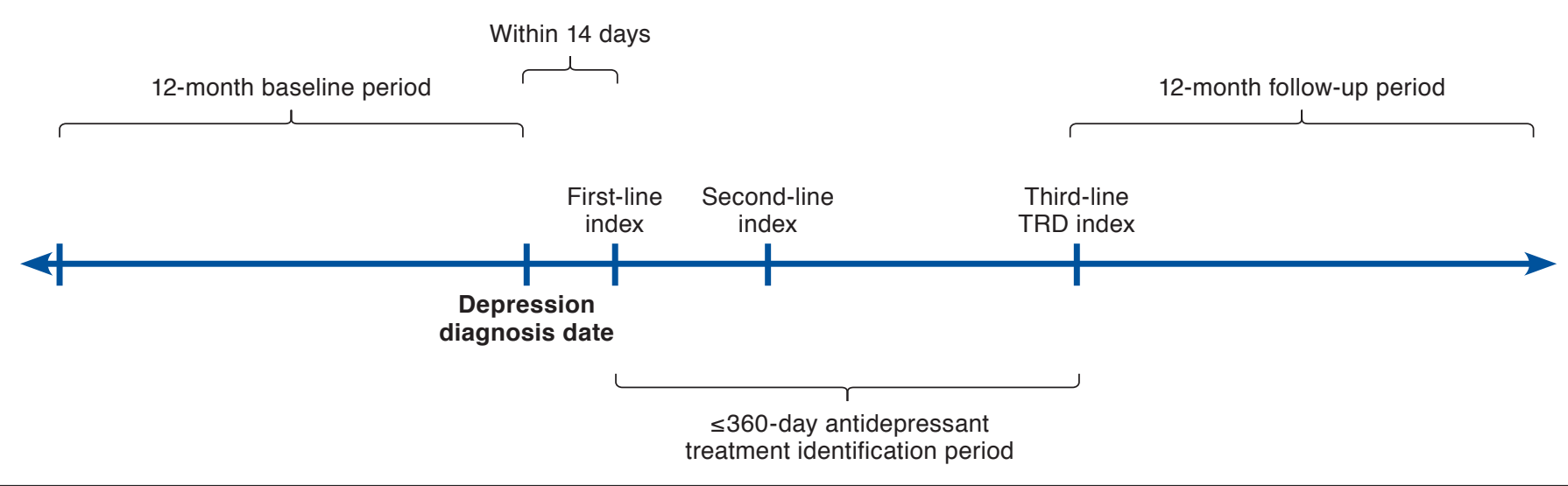

TRD = treatment-resistant depression .

APPENDIX B Annual All-Cause and Depression-Related Payments During the 12-Month Follow-up Period Among Matched Cohorts ${ }^{\mathrm{a}}$

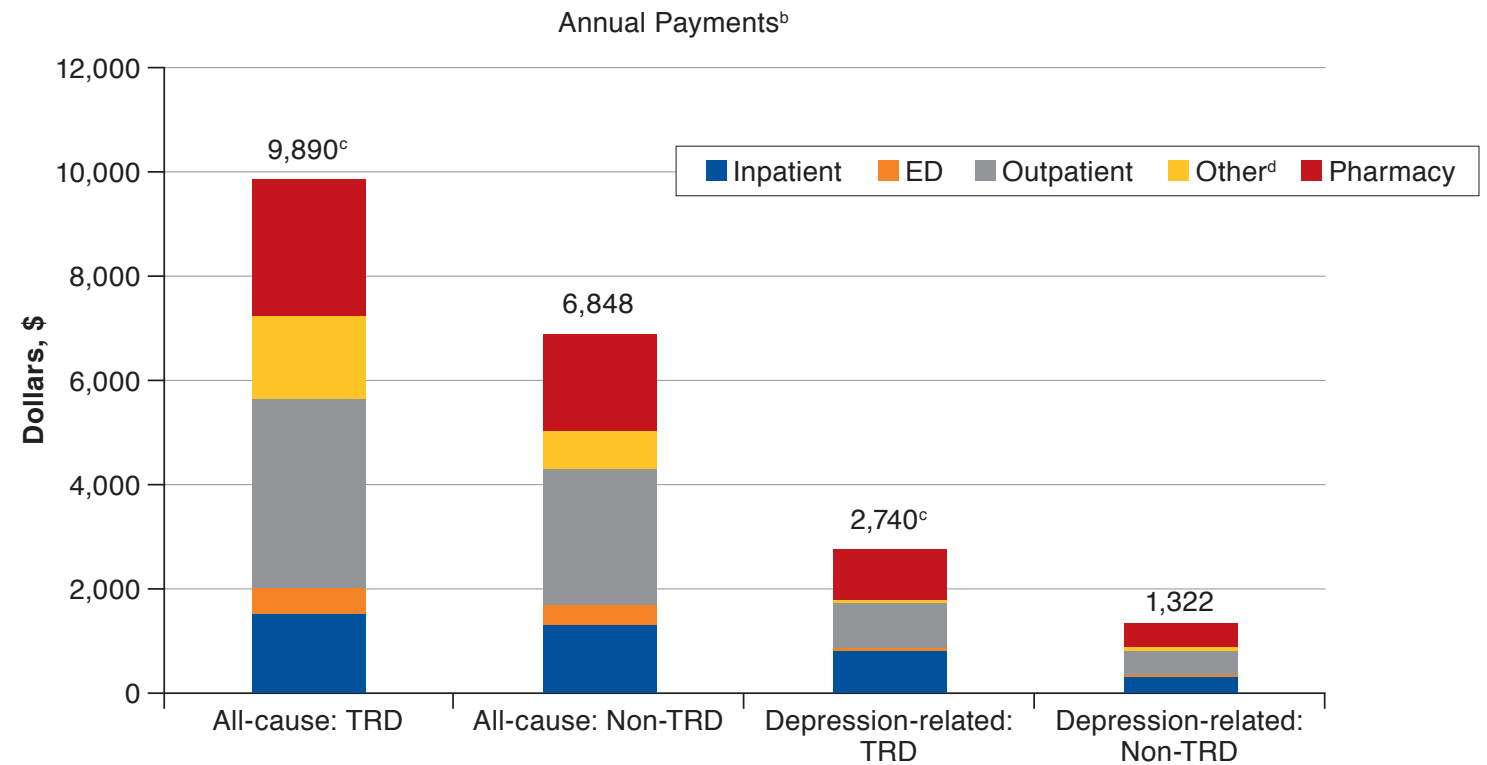

Note: All-cause and depression-related payments were compared using nonparametric Wilcoxon signed-rank tests. A P value of <0.05 was considered a statistically significant difference.

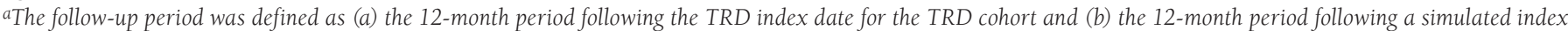
date for the non-TRD cohort.

bPayments presented in 2016 U.S. dollars.

${ }^{c}$ Results are statistically significant at $P<0.001$.

dOther includes home health care, hospice facility, inpatient rehab, outpatient psych, other location, other outpatient, skilled nursing facility, and surgical center. ED = emergency department; TRD = treatment-resistant depression. 